\title{
Possible Contribution of Mineralocorticoid Receptor Activation on Glucocorticoid-Induced Left Ventricular Remodeling in Adrenalectomized Rat
}

\author{
Kazi Rafiqul Islam ${ }^{1}$, Shamshad J. Sherajee ${ }^{2}$, Hirohito Mori ${ }^{3}$, Hideki Kobara ${ }^{4}$, Noriko Nishiyama, \\ Nazia F. Moitry ${ }^{6}$, Daisuke Nakano ${ }^{7}$, Mahbub Mostofa ${ }^{8}$ and Akira Nishiyama ${ }^{9}$
}

\begin{abstract}
Background: Chronic glucocorticoid treatment induces the development of renal injury via mineralocorticoid receptor (MR) activation in bilaterally adrenalectomized rats. It has been hypothesized that glucocorticoid contributes to the development of left ventricular (LV) remodeling through MR activation in bilaterally adrenalectomized rats (ADX).Methods: $\mathrm{ADX}$ rats were maintained with $1 \% \mathrm{NaCl}$ in drinking water and randomly treated as follows for 8 weeks: vehicle $(n=7)$, bilateral adrenalectomy $(\mathrm{ADX})+$ hydrocortisone (HYDRO) $(5 \mathrm{mg} / \mathrm{kg} /$ day, subcutaneous, $\mathrm{n}=7)$, and ADX + HYDRO + eplerenone $(0.125 \%$ in chow; approximately $75 \mathrm{mg} / \mathrm{kg} /$ day, $\mathrm{n}=7)$. An osmotic minipump was implanted subcutaneously for continuous infusion of HYDRO. Results: As compared with control vehicletreated uninephrectomized rats, ADX + HYDRO treatment for 8 weeks significantly increased systolic blood pressure, LV weight, collagen content and mRNA levels of atrial natriuretic peptide, brain natriuretic peptide, and collagen type 1 and III. These changes were associated with increase in LV thiobarbituric acid reactive substances content, dihydroethidium fluorescence and mRNA levels of NADPH oxidase subunits. Treatment with a selective MR antagonist, eplerenone significantly attenuated HYDRO induced changes in LV parameters. HYDRO-induced increases in mRNA and protein levels of serum and glucocorticoid-regulated kinases 1 were prevented by eplerenone. Conclusion: These data suggest that chronic glucocorticoid treatment induces LV tissue remodeling through MR dependent mechanism in bilateral adrenalectomized rats.
\end{abstract}

Key words: hydrocortisone, mineralocorticoid receptor, eplerenone, LV remodeling.

J Bangladesh Soc Physiol. 2013 June; 8(1): 6-15 For Authors Affiliation, see end of text.

http://www.banglajol.info/index.php/JBSP

\section{Introduction}

$\mathbf{R}$

Recently, It has been shown that chronic glucocorticoid (hydrocodevelopment of renal injury in bilateral adrenalectomized rats and mineralocorticoid receptor(MR) blockade with eplerenone

Received April 2011; $\quad$ Accepted November 2011

6 prevented hydrocortisone-induced renal injury in these animals ${ }^{1}$. Another study by Mihailidou et al. ${ }^{2}$ in Langendrph perfusion system showed that cardiac injury after myocardial infarction was aggravated by physiological dose of cortisol via MR activation without perfusion of aldosterone. Taken together, these data suggest that glucocorticoid is involved in the pathophysiology

J Bangladesh Soc Physiol. 2013, June; 8(1): 6-15 
of renal and cardiac injury through the activation of MR under experimental condition where circulating aldosterone levels are minimal. Mineralocorticoid receptor activation has been shown to play an important role in the pathogenesis of cardiovascular injury. Aldosterone/salt-treated rats developed hypertension, cardiac hypertrophy and extensive perivascular or interstitial fibrosis ${ }^{3,4}$. In the mineralocorticoid/salt-treated rats $^{5}$ and mice with chronic pressure overload ${ }^{6}$, treatment with MR antagonists provides substantial cardiovascular protection. The Randomized Aldactone Evaluation Study (RALES) ${ }^{7}$ and the Eplerenone Post-Acute Myocardial Infraction Heart Failure Efficacy and Survival Study (EPHESUS) ${ }^{8}$ have shown that treatment with MR antagonists significantly reduced mortality in patients with severe heart failure who were treated with standard medication including angiotensin converting enzyme inhibitors and angiotensin receptor blockers. Interestingly, these clinical trials also showed that the cardioprotective effects of MR antagonists were elicited even in patients whose plasma aldosterone levels were not in the pathological levels. The accumulating evidences suggest that part of these effects of MR antagonists are mediated through the mechanisms that are independent of plasma aldosterone levels, and the beneficial effects of $\mathrm{MR}$ antagonists indicate the pivotal role of MR in the development of cardiac injury.

The present study was performed to test the hypothesis that chronic hydrocortisone treatment contributes to the development of $\mathrm{LV}$ remodeling through $\mathrm{MR}$ activation in adrenalectomized rats. To test this hypothesis, we examined the effects of eplerenone, a selective MR antagonist, on LV remodeling in bilateral adrenalectomized rats. We also measured the protein and gene expression of MR target gene, serum and glucocorticoid-inducible kinase-1 (SGK1) in LV tissues.

J Bangladesh Soc Physiol. 2013, June; 8(1): 6-15

\section{Methods}

Experiments were performed on male WisterKyoto (WKY) rats (SLC, Shizuoka, Japan), having average $170 \pm 4 \mathrm{~g}$ body weight at the beginning of the experiments. Rats were maintained in a temperature-controlled $\left(24 \pm 2^{\circ} \mathrm{C}\right)$ room under a $12 \mathrm{hrs}$ light/dark cycle. All experimental procedures were performed according to the guidelines for the care and use of animals established by the Kagawa University. After one week acclimatization, male WKY rats were subjected to right uninephrectomy (UNX) and bilateral adrenalectomy (ADX) by flank incision under sodium pentobarbital anesthesia (50 mg/kg, i.p.) ${ }^{1}$.

ADX rats were put on with $1 \% \mathrm{NaCl}$ in drinking water and randomly assigned to treatment as follows for 8 weeks: vehicle $(n=7)$, bilateral adrenalectomy (ADX) + hydrocortisone (HYDRO) (5 mg/kg/day, subcutaneous, $\mathrm{n}=7)$, and ADX + HYDRO + eplerenone $(0.125 \%$ in chow; approximately $75 \mathrm{mg} / \mathrm{kg} /$ day, $\mathrm{n}=7$ ). An osmotic minipump was implanted subcutaneously for continuous infusion of HYDRO. The doses of HYDRO and eplerenone were determined on the basis of result from previous studies in rats ${ }^{1,}$ 9,10 .

Sample collections:

Systolic blood pressure (SBP) was measured by a tail-cuff plethysmography (BP-98A; Softron Co., Tokyo, Japan $)^{1}$. After 8 weeks treatment, rats were anesthetized with sodium pentobarbital (50 mg/kg, i.p.) and arterial blood was collected from abdominal aorta into chilled tubes containing EDTA. Blood samples were centrifuged, and plasma was stored at $-20^{\circ} \mathrm{C}$ for further analysis. The heart was perfused with chilled saline solution through abdominal aorta. Then, LV tissues were removed, weighed, embedded in OCT compound. Remaining LV tissues were immediately snap-frozen in liquid nitrogen and then stored at $-80^{\circ} \mathrm{C}$ for further use. The degree of cardiac hypertrophy was calculated in terms of heart weight/body weight (Hwt/bwt) ratio and 
left ventricle weight/body weight (LVwt/bwt) ratio.

Real-Time Reverse Transcription-Polymerase Chain Reaction (RT-PCR):

The mRNA expression of Glyceraldehyde-3Phosphate Dehydrogenase (GAPDH), types I and III collagen, p22phox and gp91phox in LV tissue were analyzed by real-time PCR using a LightCycler FastStart DNA Master SYBR Green I kit and an ABI Prism 7000 Sequence Detection System (Applied Biosystems, foster city, USA) ${ }^{11}$. The mRNA levels of brain natriuretic peptide (BNP), atrial natriuretic peptide (ANP) and transforming growth factor-â 1 (TGF-âl) were measured as previously described ${ }^{12}$ and MR, glucocorticoid receptor (GR), SGK1, 11âHSD2 were measured as previously described ${ }^{1}$. cDNA was initially denatured at $95^{\circ} \mathrm{C}$ for $30 \mathrm{sec}$, and then amplified by PCR for 48 cycles $\left(95^{\circ} \mathrm{C}\right.$ for 15 $\mathrm{sec}, 60^{\circ} \mathrm{C}$ for $\left.1 \mathrm{~min}\right){ }^{13,14}$. The oligonucleotide primer sequences for the rat CYP11B2 (NM_012538) are sense: 5'-AAAGAAGGTGCG TCAGAATGC-3', antisense: 5'-ACTTCAGG CTACCAGGGTTCAG-3'. All data are expressed as the relative differences compared with rats of UNX + vehicle after normalization to the expression of GAPDH.

Dihydroethidium (DHE) staining:

Fresh LV tissue was embedded in OCT and subsequently cryosectioned into $10-\mu \mathrm{m}$ sections. The sections were incubated with $10 \mathrm{imol} / \mathrm{L} \mathrm{DHE}$ (Invitrogen, Carlsbad, California, USA) in PBS at $37^{\circ} \mathrm{C}$ for $30 \mathrm{~min}$ in the light-protected humidified chamber ${ }^{15}$. Once DHE is oxidized to ethidium, it intercalates within DNA, staining the nucleus a fluorescent red. Images were obtained by confocal laser-scanning fluorescence microscopy system (Radiance2100; Bio-Rad Laboratories, Hercules, California, USA). The DHE fluorescence intensity was calculated from seven samples in each group.
Western blot analysis:

SGK1 protein expression was determined by Western blotting analysis with SGK-specific antibody as described previously ${ }^{16}$. Briefly, protein samples were separated by $8 \%$ SDSpolyacrylamide gel electrophoresis and then transferred to nitrocellulose membrane (GE Healthcare Life Science, Buckinghamshire, UK). The membrane was incubated with an anti-SGK1 (MR 1-18 1D5) antibody (1:500; Cell Signaling Technology, Inc., MA, USA), followed by incubation with horseradish peroxidaseconjugated anti-mouse immunoglobulin G (1:10,000; Jackson ImmunoResearch Laboratories, West Grove, PA). Finally, the bands were detected by chemiluminescence using the ECL plus Western blotting detection system (GE Healthcare Life Science) following the manufacturer's instructions. To check for equal loading, membranes were reprobed with an antibody against â-actin (Sigma). All values were expressed as the relative differences compared with rats of UNX + vehicle after normalization to the expression of â-actin.

Other analytical procedures:

The degrees of lipid peroxidation in plasma and LV tissues were determined using biochemical assays of the thiobarbituric acid reactive substances (TBARS), as described previously ${ }^{10,11}$. Collagen content in the LV tissues was determined on the basis of hydroxyproline concentration as described previously ${ }^{17}$. The value of collagen content was expressed as microgram per milligram of dry tissue weight. Plasma aldosterone, sodium and potassium concentration were measure as previously reported ${ }^{1}$.

All values are presented as the means \pm SEM. Data were compared using one-way ANOVA followed by Newman-Keuls post-hoc multiple comparisons test. $P$ values below 0.05 were considered statistically significant. Data and statistical analyses were performed using GraphPad Prism version 5 for Windows (Graph Pad Software, San Diego, CA, USA).

J Bangladesh Soc Physiol. 2013, June; 8(1): 6-15 


\section{Results}

Biological and biochemical parameters:

After 8 weeks treatment, plasma aldosterone concentration was remained below the detectable ranges in uninepherctomized-bilateral adrenalectomized rats $(<13 \mathrm{pg} / \mathrm{mL})$, suggesting the completeness of bilateral adrenalectomy. In contrast, plasma aldosterone concentration was averaged $190 \pm 39 \mathrm{pg} / \mathrm{mL}$ in control rats. Plasma HYDRO concentration in HYDRO infused-ADX rats and $\mathrm{HYDRO}$-infused $\mathrm{ADX}$ rats treated with eplerenone were $36 \pm 4$ and $37 \pm 5 \mathrm{ng} / \mathrm{mL}$, respectively. Systolic blood pressure was significantly increased in HYDRO-infused rats compared to control rats $(175 \pm 5$ and $112 \pm 3 \mathrm{mmHg}$, $P<0.01)$. There was no significant difference in SBP between HYDRO-infused rats and HYDROinfused rats treated with eplerenone $(170 \pm 3$ $\mathrm{mmHg}$ ). Plasma sodium and potassium levels were not different among the groups (data not shown).

Cardiac hypertrophy markers:

HYDRO-infused rats showed significantly higher Hwt/bwt and LVwt/bwt compared to control rats (Figures 1A, B). Eplerenone treatment prevented HYDRO-induced increases in Hwt/bwt and LVwt/ bwt ratio. As shown in Figures $1 \mathrm{C}$ and $\mathrm{D}$, HYDRO-infused rats showed significantly increased ANP and BNP mRNA expression in LV tissues compared to control rats, a marker of cardiac hypertrophy ${ }^{18}$. Treatment with eplerenone attenuated HYDRO-induced increase in mRNA levels of ANP and BNP.

Cardiac collagen and fibrotic markers:

As shown in Figure 2A, HYDRO-infused rats showed significantly higher collagen contents in LV tissues compared to control rats. Treatment with eplerenone markedly attenuated HYDROinduced increases in collagen contents in LV tissues. Collagen types I and III mRNA levels in LV tissues were significantly increased in HYDRO-infused rats (Figures $2 \mathrm{C}$ and $\mathrm{D}$ respectively), whereas TGF-âl mRNA levels

J Bangladesh Soc Physiol. 2013, June; 8(1): 6-15 tends to be increased in HYDRO-infused rats which was not statistically significant (Figures 2B). Treatment with eplerenone prevented HYDRO-induced increases in mRNA levels of TGF-â1, collagen types I and III.

Cardiac oxidative stress:

As shown in Figures 3A and B, HYDRO-infused rats showed significantly higher TBARS levels in plasma and LV tissues. Concurrent treatment with eplerenone significantly attenuated HYDRO-induced increases TBARS levels in both plasma and LV tissues. NADPH oxidase subunits, p22phox and gp91phox, mRNA levels in LV tissues were significantly upregulated in HYDRO-infused rats compared to control rats (Figures 3C and D). Treatment with eplerenone prevented the HYDRO-induced upregulation of NADPH oxidase subunits mRNA expression in LV tissues. In addition, HYDRO-infused rats showed markedly increased DHE fluorescence in LV tissues (Figure 3E). Treatment with eplerenone prevented HYDRO-induced increase DHE fluorescence in LV tissues. The beneficial effects of MR blockage indicate that HYDRO participates in the MR-dependent pathophysiological response in the heart of adrenalectomized rats.

Gene expressions of SGK1, 11â-HSD2, MR and aldosterone synthase (CYP11B2):

As shown in Figures $4 \mathrm{~A}$ and $\mathrm{B}, \mathrm{mRNA}$ and protein levels of SGK1, a MR target gene, were significantly upregulated in LV tissues of HYDRO-infused rats compared to control rats. Concurrent treatment with eplerenone significantly attenuated HYDRO-induced upregulation of both mRNA expression and protein of SGK1 in LV tissues. On the other hand, all of the groups exhibited detectable 11â-HSD2 gene expression, which were similar among the groups (Table I). MR and GR mRNA levels were not significantly different among the groups (Table I). CYP11B2 gene expression in LV tissues was detectable, and was similar among the groups (Table I). 
Table I: Gene expressions in LV tissues of experimental rats.

\begin{tabular}{lccc}
\hline Genes & \multicolumn{3}{c}{ Treatment groups } \\
\cline { 2 - 4 } & $\begin{array}{c}\text { UNX+vehicle } \\
(\mathrm{n}=7)\end{array}$ & $\begin{array}{c}\text { UNX+ADX } \\
+ \text { HYDRO }(\mathrm{n}=7)\end{array}$ & $\begin{array}{c}\text { UNX+ADX } \\
\text { +HYDRO +eplerenone }(\mathrm{n}=7)\end{array}$ \\
\hline MR & $1 \pm 0.16$ & $0.88 \pm 0.15$ & $0.90 \pm 0.15$ \\
GR & $1 \pm 0.25$ & $1.08 \pm 0.16$ & $1.17 \pm 0.09$ \\
$11 \mathrm{~b}-\mathrm{HSD} 2$ & $1 \pm 0.18$ & $1.08 \pm 0.14$ & $1.15 \pm 0.08$ \\
CYP11B2 & $1 \pm 0.21$ & $0.80 \pm 0.11$ & $0.90 \pm 0.17$ \\
\hline
\end{tabular}

Each value represents the mean \pm SEM. Data are expressed as the relative differences in compared with UNX + vehicle after normalization to the expression of GADPH. UNX; unephrectomized, ADX; bilateral adrealectomized, HYDRO; hydrocortisone, MR; mineralocorticoid receptor, GR; glucocorticoid receptor, 11âHSD2; 11âhydroxysteroid dehydrogenase type 2, and CYP11B2; aldosterone synthase.

\section{UNX + vehicle}

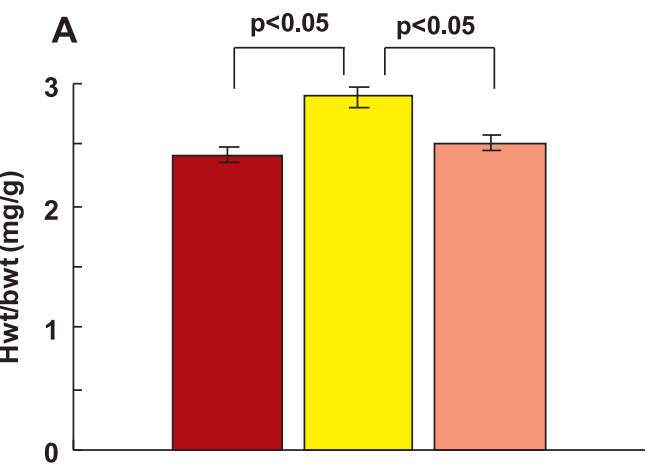

C

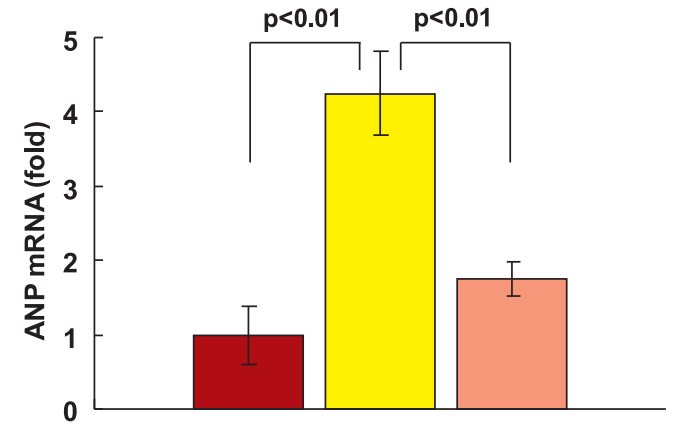

UNX + ADX + HYDRO + eplerenone

\section{B}

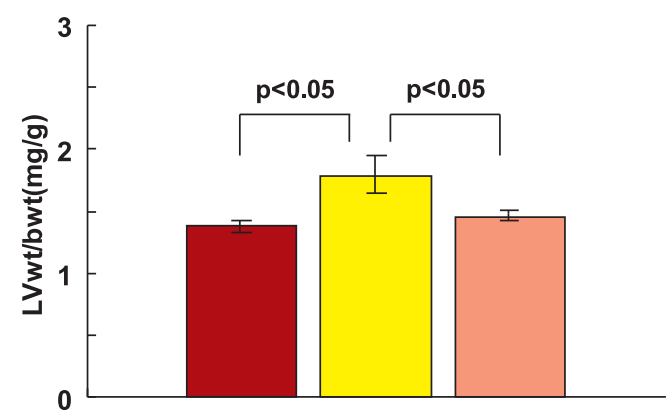

D

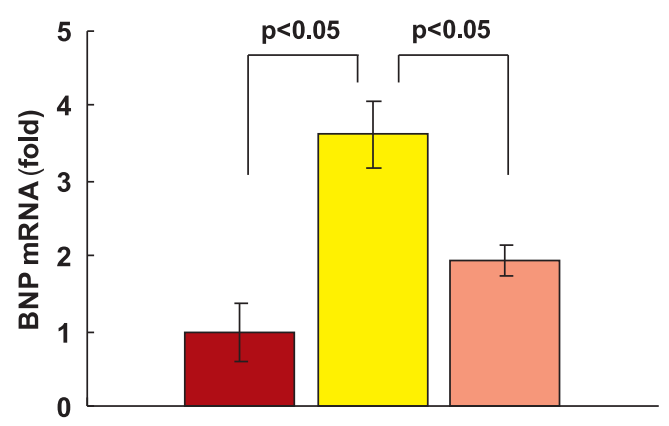

Figure 1. Heart weight to body weight ratio (Hwt/bwt) (A), Left ventricular weight to body weight ratio (LVwt/bwt) (B). Atrial natriuretic peptides (ANP) (C), Brain natriuretic peptide (BNP) (D) mRNA levels in LV tissues analyzed by semiquantitative real-time RT-PCR. RT-PCR data are expressed as the relative differences in compared with UNX + vehicle after normalization to the expression of Glyceraldehyde-3-Phosphate Dehydrogenase (GAPDH). UNX; unephrecto-mized, ADX; bilateral adrealectomized, HYDRO; hydrocortisone. 


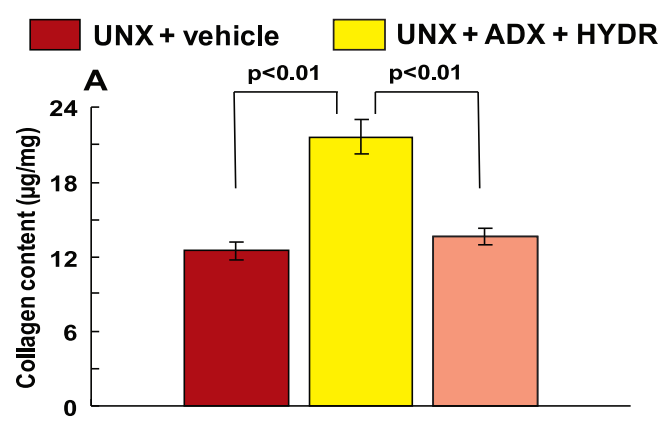

UNX + ADX + HYDRO + eplerenone
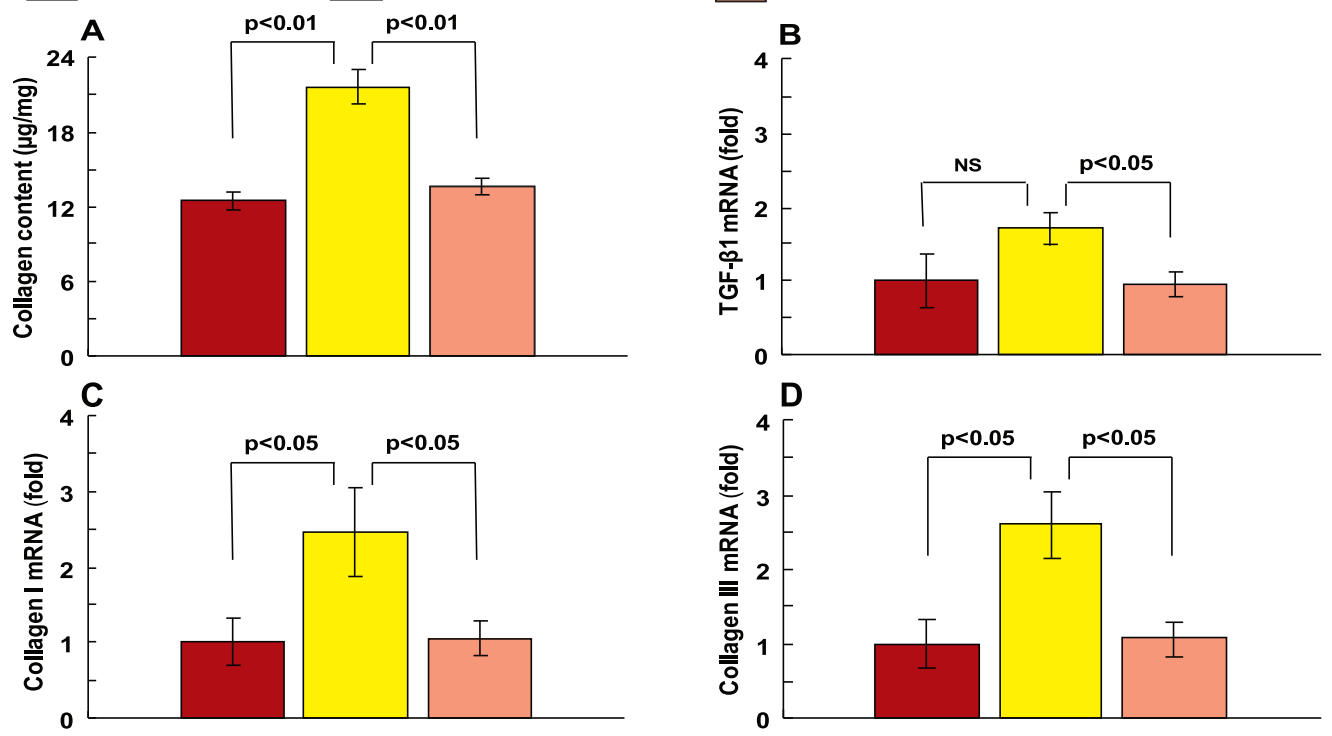

Figure 2. LV tissues collagen content (A) analyzed on the basis of hydroxyproline concentration. TGF-âl (B), Collagen type I (C) and Collagen type III (D) mRNA levels in LV tissues of experimental rats. All RT-PCR data are expressed as the relative differences in compared with UNX + vehicle after normalization to the expression of GADPH. NS; not significant.

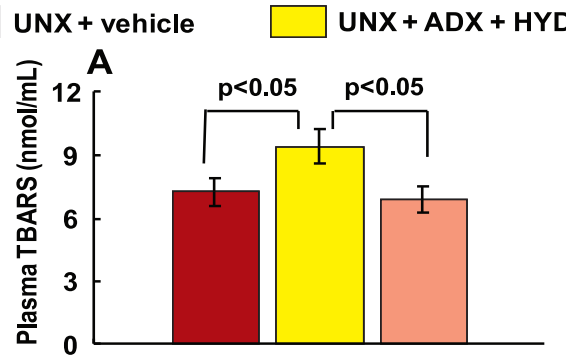

C

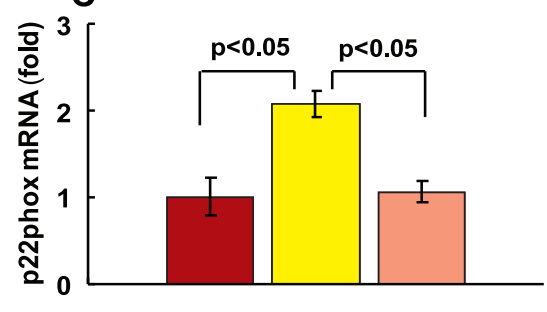

E

UNX + vehicle
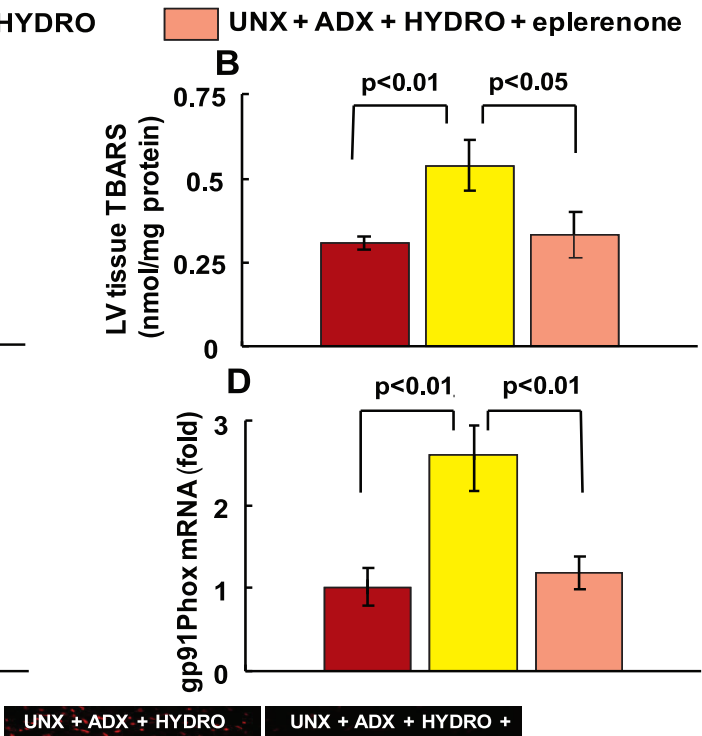

UNX + ADX + HYDRO +

eplerenone
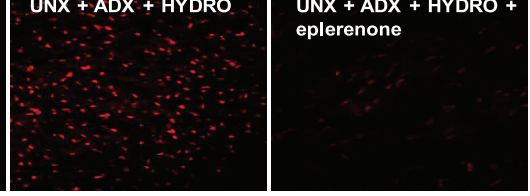

Figure 3. Thiobarbituric acid reactive substances (TBARS) levels in plasma (A) and LV tissues (B). P22 phox (C) and gp91phox (D) mRNA levels in LV tissues of experimental rats. Representative image of dihydroethidium (DHE) staining from LV tissues (original magnification, X200) (E). Data from RT-PCR expressed as the relative differences in compared with UNX + vehicle after normalization to the expression of GADPH. 
UNX+ vehicle

UNX + ADX + HYDRO

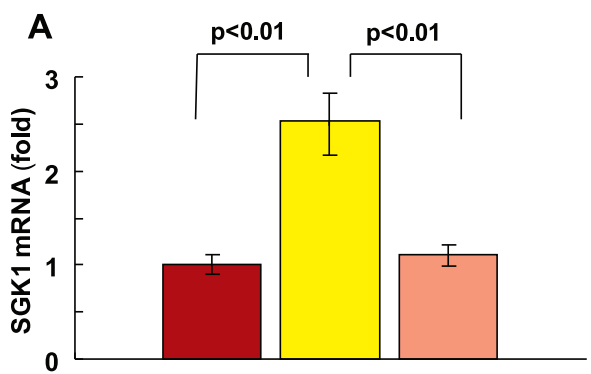

\section{UNX + ADX + HYDRO + eplerenone}
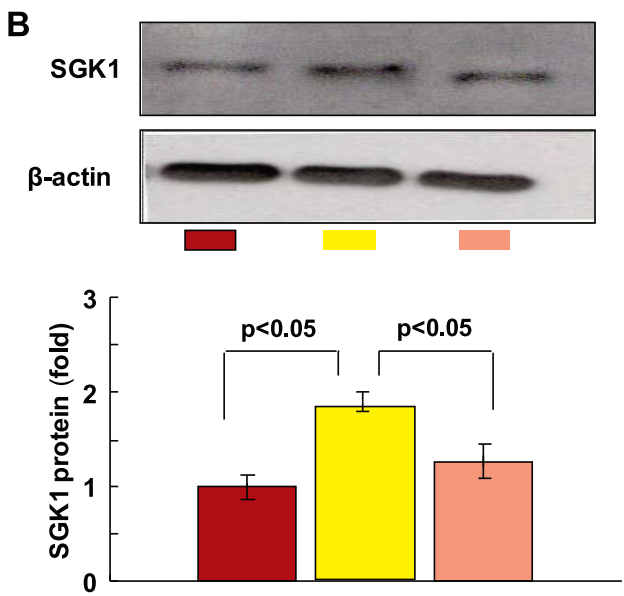

Figure 4. LV tissues mRNA expression (A) and protein (B) of SGK1 analyzed by RT-PCR and western blot, respectively. SGK1 protein levels were normalized by arbitrarily setting the integrated densitometric values of UNX + vehicle after normalization to â-actin.

\section{Discussion}

The present study showed that chronic HYDRO treatment induces LV hypertrophy, collagen accumulation and oxidative stress in bilateral adrenalectomized rats, and was associated with increased SGK1 gene and protein levels. Furthermore, MR blockade by eplerenone attenuates the HYDRO-induced cardiac remodeling. These data support the hypothesis that chronic glucocorticoid treatment induces cardiac remodeling through MR activation in bilateral adrenalectomized rats.

Cushing's syndrome is associated with increased mortality and morbidity in patient due to cardiac diseases including LV hypertrophy ${ }^{19,20}$. In agreement with previous study by another group $^{18}$, we showed HYDRO-induced LV hypertrophy was accompanied by increases in ANP and BNP mRNA levels. HYDRO-induced elevated natriuretic peptide levels were attenuated by MR blockade with eplerenone in adrenalectomized rats. Previous study showed that natriuretic peptide expression increased during MR activation in the heart ${ }^{21}$. In addition, in vitro study showed that MR activation induced cardiomyocyte hypertrophy and increased BNP transcription ${ }^{22}$. These data support the concept that cardiac MR can be activated by chronic glucocorticoid treatment in bilateral adrenalectomized rats.

Extracellular matrix plays an important role in regulating cardiovascular function ${ }^{23}$. Increased deposition of collagen in the extracellular matrix leads to fibrosis which associates with contractile abnormality in the heart ${ }^{24}$. In the present study, HYDRO infusion increased the collagen mRNA expression and content in LV tissues, which were significantly attenuated by eplerenone in adrenalectomized rats. These data suggest that chronic glucocorticoid treatment induces LV fibrosis possibly through MR activation in adrenalectomized rats. However, a weak point of this study is that cardiac fibrosis was not examined by histological analysis.

In the earlier report Funder proposed that glucocorticoid-MR complexes can be transcriptionally activated as a result of the generation of reactive oxygen species (ROS) ${ }^{25}$. In the present study, HYDRO-infused rats showed increases in TBARS levels in plasma and $\mathrm{LV}$ tissues, as well as gene expression of NADPH

J Bangladesh Soc Physiol. 2013, June; 8(1): 6-15 
oxidase components and DHE fluorescence in LV tissues. These data suggest that chronic HYDRO treatment develops cardiac remodeling through NADPH oxidase-dependent ROS production, at least in part. Therefore, in agreement with the proposal of Michea et al. ${ }^{26}$ it is also possible that the increased oxidative stress may also lead to further activation of MR which are preoccupied by HYDRO in this pathophysiological condition. In contrast, Young et $a l .{ }^{27}$ reported that eight days exogenous glucocorticoid infusion developed cardiovascular inflammation through activation of MR in adrenalectomized rats. In these experiments, treatment with physiological dose of corticosterone did not increase gene expression of NADPH oxidase subunits whereas numbers of extravasated macrophages were increased in the heart ${ }^{27}$.

In the present study, mRNA of SGK1 was evaluated as a potential marker for cardiac MR activation $^{28,29}$. In HYDRO-infused rats, cardiac remodeling was associated with marked increases in both mRNA and protein levels of SGK 1 in LV tissues. Importantly, treatment with eplerenone significantly attenuated the increases in LV SGK1 levels, indicating HYDRO-infusion induces MR activation as well as stimulates a classical function of MR transcription. These data support the concept that chronic HYDRO treatment activates LV MR in adrenalectomized rats.

The functional role of 11âHSD2 in the heart is controversial. Several studies showed that 11 âHSD2 is not expressed in cardiomyocytes ${ }^{30}$ or heart ${ }^{31}$. However, Michea et al. ${ }^{26}$ reported that both 11âHSD2 activity and gene expressions are detectable in LV of rats. In the present study, gene expression of 11âHSD2 in LV tissues was detectable which were not altered by HYDRO infusion. The possibility of local production of steroids (both mineralocorticoid and glucocorticoid) in the heart is also controversial. Several studies have indicated that most of the aldosterone in the heart is derived from the circulation $^{32,33}$. In contrast, Silvestre et al. ${ }^{34}$ reported the existence of endocrine steroidogenic system in rat heart. In addition, other study also indicated that aldosterone is synthesized in the heart $^{35}$. In this aspect present study showed that aldosterone synthase (CYP11B2) gene expression in LV tissues were detectable, and was similar among the groups.

\section{Conclusion}

The present study suggests that cardiac MR could be activated by HYDRO, and that the HYDROinduced MR activation participates in the development of cardiac remodeling in bilateral adrenalectomized rats. Clinically present study findings imply that chronic treatment with steroids which stimulate MR in vivo may induce LV remodeling. Furthermore, MR blockers may have cardioprotective effect in patients chronically treated with steroids that activate MR or Cushing's syndrome patients with cardiac abnormality. The limitation of the present study is the lack of LV functional and histological data. Future studies are needed to determine the functional and histological changes induced by HYDRO infusion in bilateral adrenalectomized rats.

\section{Authors Affiliation}

1. *Kazi Rafiq, JSPS Postdoc Fellow, Department of Pharmacology, Faculty of Medicine, Kagawa University, 1750-1 Ikenobe, Miki-cho, Kita-gun, Kagawa 7610793 Japan. Email: krafiq73 @yahoo.com

2. Shamshad J. Sherajee, Postdoc Fellow, Department of Pharmacology, Faculty of Medicine, Kagawa University, Japan

3. Hirohito Mori, Associate Professor, Department of Gastroenterology and Neurology, Faculty of Medicine, Kagawa University, Japan

4. Hideki Kobara, Associate Professor, Department of Gastroenterology and Neurology, Faculty of Medicine, Kagawa University, Japan

5. Noriko Nishiyama, Lecturer, Department of Gastroenterology and Neurology, Faculty of Medicine, Kagawa University, Japan

6. Nazia F. Moitry, Faridpur Medical College, Faridpur, Bangladesh.

7. Daisuke Nakano, Assistant Professor, Department of Pharmacology, Faculty of Medicine, Kagawa University, Japan

8. Mahbub Mostofa, Professor, Department of Pharmacology, Bangladesh Agricultural University, Mymensingh, Bangladesh

9. Akira Nishiyama, Professor, Dept. of Pharmacology, Faculty of Medicine, Kagawa University, Japan

*For correspondence 


\section{References}

1. Rafiq K, Nakano D, Ihara G, Hitomi H, Fujisawa Y, Ohashi N, et al. Effects of mineralocorticoid receptor blockade on glucocorticoid-induced renal injury in adrenalectomized rats. J Hypertens 2011;29:290-298.

2. Mihailidou AS, Loan Le TY, Mardini M, and Funder JW. Glucocorticoids activate cardiac mineralocorticoid receptors during experimental myocardial infarction. Hypertension 2009;54:1306-1312.

3. Brilla CG, and Weber KT. Mineralocorticoid excess, dietary sodium, and myocardial fibrosis. J Lab Clin Med 1992;120:893-901.

4. Young M, Fullerton M, Dilley R, and Funder JW. Mineralocorticoids, hypertension, and cardiac fibrosis. J Clin Invest 1994;93:2578-2583.

5. Young M, and Funder JW. Eplerenone, but not steroid withdrawal, reverses cardiac fibrosis in deoxycorticosterone/salt-treated rats. Endocrinology 2004;145:3153-3157.

6. Kuster GM, Kotlyar E, Rude MK, Siwik DA, Liao $\mathrm{R}$, Colucci WS, et al. Mineralocorticoid receptor inhibition ameliorates the transition to myocardial failure and decreases oxidative stress and inflammation in mice with chronic pressure overload. Circulation 2005;111:420-427.

7. Pitt B, Zannad F, Remme WJ, Cody R, Castaigne A, Perez A, et al. The effect of spironolactone on morbidity and mortality in patients with severe heart failure. Randomized Aldactone Evaluation Study Investigators. N Engl J Med 1999;341:709717.

8. Pitt B, Remme W, Zannad F, Neaton J, Martinez F, Roniker B, et al. Eplerenone, a selective aldosterone blocker, in patients with left ventricular dysfunction after myocardial infarction. $\mathrm{N}$ Engl J Med 2003;348:1309-1321.

9. Otsuki M, Okabayashi Y, Ohki A, Suehiro I, Nakamura T, Fujii M, et al. Effects of hydrocortisone on glucose- and cholecystokinininduced insulin release from the isolated perfused rat pancreas. Pancreas 1988;3:459-464.

10. Nishiyama A., Yao L, Nagai Y, Miyata K, Yoshizumi M, Kagami S, et al. Possible contributions of reactive oxygen species and mitogen-activated protein kinase to renal injury in aldosterone/salt-induced hypertensive rats. Hypertension 2004;43:841-848.
11. Rahman M, Nishiyama A, Guo P, Nagai Y, Zhang GX, Fujisawa Y, et al. Effects of adrenomedullin on cardiac oxidative stress and collagen accumulation in aldosterone-dependent malignant hypertensive rats. J Pharmacol Exp Ther 2006;318:1323-1329.

12. Guo P, Nishiyama A, Rahman M, Nagai Y, Noma $\mathrm{T}$, Namba T, et al. Contribution of reactive oxygen species to the pathogenesis of left ventricular failure in Dahl salt-sensitive hypertensive rats: effects of angiotensin II blockade. J Hypertens 2006;24:10971104.

13. Ferrari P. Cortisol and the renal handling of electrolytes: role in glucocorticoid-induced hypertension and bone disease. Best Pract Res Clin Endocrinol Metab 2003;17:575-589.

14. Thunhorst RL, Beltz TG, and Johnson AK. Glucocorticoids increase salt appetite by promoting water and sodium excretion. Am J Physiol Regul Integr Comp Physiol 2007;293:R1444-1451.

15. Fan YY, Kohno M, Nakano D, Ohsaki H, Kobori $\mathrm{H}$, Suwarni D, et al. Cilnidipine suppresses podocyte injury and proteinuria in metabolic syndrome rats: possible involvement of $\mathrm{N}$-type calcium channel in podocyte. J Hypertens 2010;28:1034-1043.

16. Terada Y, Kuwana H, Kobayashi T, Okado T, Suzuki N, Yoshimoto T, et al. Aldosterone-stimulated SGK1 activity mediates profibrotic signaling in the mesangium. J Am Soc Nephrol 2008;19:298-309.

17. Noma T, Mizushige K, Yao L, Yu Y, Kiyomoto H, Hosomi N, et al. Alteration in aortic wall stiffness and accumulation of collagen during the prediabetic stage of type II diabetes mellitus in rats. Jpn Circ J 1999;63:988-993.

18. Roy SG, De P, Mukherjee D, Chander V, Konar A, Bandyopadhyay D, et al. Excess of glucocorticoid induces cardiac dysfunction via activating angiotensin II pathway. Cell Physiol Biochem 2009;24:1-10.

19. Baykan M, Erem C, Gedikli O, Hacihasanoglu A, Erdogan T, Kocak M, et al. Assessment of left ventricular diastolic function and Tei index by tissue Doppler imaging in patients with Cushing's Syndrome. Echocardiography 2008;25:182-190.

20. Boscaro M, Barzon L, Fallo F, and Sonino N. Cushing's syndrome. Lancet 2001;357:783-791.

21. Dananberg J, and Grekin RJ. Corticoid regulation of atrial natriuretic factor secretion and gene expression. Am J Physiol 1992;263:H1377-1381.

J Bangladesh Soc Physiol. 2013, June; 8(1): 6-15 
22. Yamamuro M, Yoshimura M, Nakayama M, Abe K, Shono M, Suzuki S, et al. Direct effects of aldosterone on cardiomyocytes in the presence of normal and elevated extracellular sodium. Endocrinology 2006;147:1314-1321.

23. Brower GL, Gardner JD, Forman MF, Murray DB, Voloshenyuk T, Levick SP, et al. The relationship between myocardial extracellular matrix remodeling and ventricular function. Eur J Cardiothorac Surg 2006;30:604-610.

24. Weber KT, and Brilla CG. Pathological hypertrophy and cardiac interstitium. Fibrosis and reninangiotensin-aldosterone system. Circulation $1991 ; 83: 1849-1865$.

25. Funder JW. RALES, EPHESUS and redox. J Steroid Biochem Mol Biol 2005;93:121-125.

26. Michea L, Villagran A, Urzua A, Kuntsmann S, Venegas P, Carrasco L, et al. Mineralocorticoid receptor antagonism attenuates cardiac hypertrophy and prevents oxidative stress in uremic rats. Hypertension 2008;52:295-300.

27. Young MJ, Morgan J, Brolin K, Fuller PJ, and Funder JW. Activation of mineralocorticoid receptors by exogenous glucocorticoids and the development of cardiovascular inflammatory responses in adrenalectomized rats. Endocrinology 2010;151:2622-2628.

28. Lister K, Autelitano DJ, Jenkins A, Hannan RD, and Sheppard KE. Cross talk between corticosteroids and alpha-adrenergic signalling augments cardiomyocyte hypertrophy: a possible role for SGK1. Cardiovasc Res 2006;70:555-565.
29. Vallon V, Wyatt AW, Klingel K, Huang DY, Hussain A, Berchtold S, et al.. SGK1-dependent cardiac CTGF formation and fibrosis following DOCA treatment. J Mol Med 2006;84:396-404.

30. Sheppard KE, and Autelitano DJ. 11Betahydroxysteroid dehydrogenase 1 transforms 11 dehydrocorticosterone into transcriptionally active glucocorticoid in neonatal rat heart. Endocrinology 2002;143:198-204.

31. Wang H, Shimosawa T, Matsui H, Kaneko T, Ogura S, Uetake Y, et al. Paradoxical mineralocorticoid receptor activation and left ventricular diastolic dysfunction under high oxidative stress conditions. J Hypertens 2008;26:1453-1462.

32. Chai W, Garrelds IM, de Vries R, and Danser AH. Cardioprotective effects of eplerenone in the rat heart: interaction with locally synthesized or bloodderived aldosterone? Hypertension 2006;47:665670 .

33. Gomez-Sanchez EP, Ahmad N, Romero DG, and Gomez-Sanchez CE. Origin of aldosterone in the rat heart. Endocrinology 2004;145:4796-4802.

34. Silvestre JS, Robert V, Heymes C, Aupetit-Faisant B, Mouas C, Moalic JM, et al. Myocardial production of aldosterone and corticosterone in the rat. Physiological regulation. J Biol Chem 1998;273:4883-4891.

35. White PC. Aldosterone: direct effects on and production by the heart. J Clin Endocrinol Metab 2003; 88: 2376-2383. 